\title{
Dissociated visual perceptual and spatial deficits in focal lesions of the right hemisphere
}

\author{
FREDA NEWCOMBE AND W. RITCHIE RUSSELL \\ From the Department of Neurology, Churchill Hospital, Oxford
}

Recent clinical and experimental studies of patients with unilateral lesions have been more concerned with problems of hemispheric asymmetry than with the somewhat limited notion of cerebral dominance. There are now firm data to support the observation of earlier clinicians (Hughlings Jackson, 1887; Pötzl, 1928; Lange, 1936; Dide, 1938) that the right hemisphere plays a special part in visual perception and spatial orientation (McFie, Piercy, and Zangwill, 1950; Anderson, 1951; Hécaen, Ajuriaguerra, and Massonnet, 1951; McFie and Piercy, 1952; Milner, 1952; Ettlinger, Warrington, and Zangwill, 1957; Milner, 1958; Costa and Vaughan, 1962; Hécaen, 1962; Teuber, 1962).

Moreover, the question of regional specialization of function within the hemispheres, recently reviewed by Piercy (1964), has been illustrated by reports of highly selective intellectual deficit in patients with focal brain lesions (Milner, 1963, 1967). Studies of temporal-lobe epilepsy have shown an association between right temporal-lobe lesions and pattern-recognition deficits (Milner, 1958; Kimura, 1963; Meier and French, 1965); and work on neurological patients with right parietal or posterior lesions has revealed deficits in visual perception (Warrington and James, 1967a, b), block design (McFie and Piercy, 1952), picture description (Ettlinger, 1960), and spatial orientation (Paterson and Zangwill, 1944; Critchley, 1953; De Renzi, 1967).

The present study, which was part of a project designed to investigate the long-term effects of focal missile injury to the brain (Newcombe, 1969), was based on the hypothesis of hemispheric asymmetry of function-that is, the leading rôle of the left hemisphere for language functions and of the right hemisphere for visual-perceptual and spatial functions. But it was also designed to explore the nature of differentiation of function within the hemispheres, and did in fact provide evidence of dissociated visual-perceptual and spatial deficits following posterior lesions of the right hemisphere.

\section{METHOD}

SUBJECTS Eighty-one right-handed subjects with focal, unilateral, missile injury to the brain were selected from a group of 153 pensioners of the second world war who were examined in the Department of Neurology, Churchill Hospital, between 1963 and 1966. (Men with midline or bilateral injuries, and those with left-handed tendencies were excluded from the present sample). Forty-four of the experimental subjects had unilateral lesions of the left hemisphere (LH group) and 37 men had right hemisphere lesions (RH group). The two groups did not differ significantly in age or vocabulary level, and were matched in these respects with the control groups. Control subjects were hospital patients who volunteered to participate during their brief admission for minor surgery. Two control groups were used, one for each experimental task, but 20 subjects were included in both control groups. The relevant data for experimental and control subjects are shown in Table I.

The locus of lesion for each experimental subject was charted according to procedures described elsewhere (Russell, 1947; Russell and Espir, 1961); the charting was based on operation reports and on lateral and anterior-posterior radiographs. The two experimental groups were then classified according to locus of lesion

TABLE I

AGE AND VOCABULARY SCORES FOR EXPERIMENTAL AND CONTROL GROUPS

\begin{tabular}{|c|c|c|c|c|c|c|c|c|}
\hline \multirow[b]{2}{*}{ Scores } & \multicolumn{8}{|c|}{ Group } \\
\hline & $\begin{array}{l}L H(n= \\
(\text { mean) }\end{array}$ & 4) & $\begin{array}{c}R H(n= \\
\text { (mean) }\end{array}$ & (SD) & $\begin{array}{l}\text { Control } \\
\text { (mean) }\end{array}$ & $\begin{array}{c}n=53) \\
(S D)\end{array}$ & $\begin{array}{l}\text { Control } \\
\text { (mean) }\end{array}$ & $\begin{array}{c}(n=43) \\
(S D)\end{array}$ \\
\hline $\begin{array}{l}\text { Age } \\
\text { Mill Hill Vocabulary IQ }\end{array}$ & $\begin{array}{l}45 \cdot 23 \\
97 \cdot 68\end{array}$ & $\begin{array}{r}5 \cdot 70 \\
12 \cdot 53\end{array}$ & $\begin{array}{r}46 \cdot 65 \\
103 \cdot 73\end{array}$ & $\begin{array}{r}5 \cdot 24 \\
12 \cdot 70\end{array}$ & $\begin{array}{r}45 \cdot 62 \\
102 \cdot 04\end{array}$ & $\begin{array}{r}7 \cdot 50 \\
11 \cdot 25\end{array}$ & $\begin{array}{c}47 \cdot 02 \\
101 \cdot 77\end{array}$ & $\begin{array}{c}7 \cdot 07 \\
11 \cdot 85\end{array}$ \\
\hline
\end{tabular}


as follows: frontal (that is, a lesion confined to the frontal lobe); temporal or temporo-parietal; parietal (that is, a lesion confined to the parietal lobe); posterior (that is, lesions damaging the occipital lobes-for example, occipital, parieto-occipital, and temporooccipital lesions); and a mixed group (that is, frontotemporal and fronto-parietal lesions).

MATERIAL The experimental subjects were given a number of verbal and visual-spatial tasks which included a visual 'closure' test and a visually-guided stylus-maze task. The 'closure' material (Mooney, 1956, 1957) consists of black and white drawings of human faces with exaggerated shadows and highlights (see Fig. 1). Each face was presented on a separate card, $10 \times 6.5 \mathrm{~cm}$ in size, and the subject worked through a pack of 40 cards, saying whether he could recognize the face as that of a man, a woman, an old man, an old woman, a boy, or a girl. He was not allowed more than 30 seconds for each card. For the present investigation the first 40 faces in Lansdell's $(1961,1968)$ revised series were used; each correct response was scored 1 , with a maximum score of 40. Guessing was not encouraged.

The apparatus for the maze task consisted of 64 raised blocks ( $2 \mathrm{~cm}$ square), outlined by grooves in a network $21 \mathrm{~cm}$ square (see Fig. 2). Paths graded according to
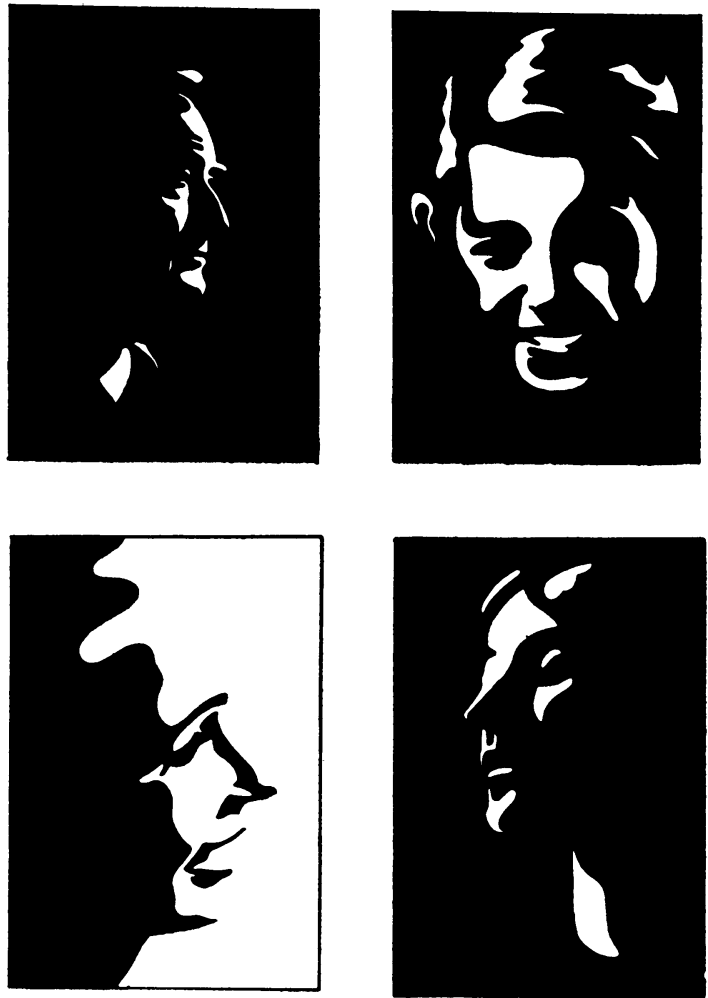

FIG. 1. Visual 'closure' task: examples of materials. number of choice points were wired into circuit and could be switched on in turn. The subject ran a stylus along the grooves and over brass studs at the intersection points. If he turned in the wrong direction a red light switched on with an audible click; no lights or sounds were produced by a correct move. The first path had six choice points and the second path ten choice points (see Fig. 3). The first path was regarded as a practice run, to ensure that instructions and procedure were understood. In each case the path was quickly demonstrated-in one move without pausing at choice points, and subjects were asked to find the correct path. In case of error they were told to return to the preceding choice point; they were advised not to hurry and informed

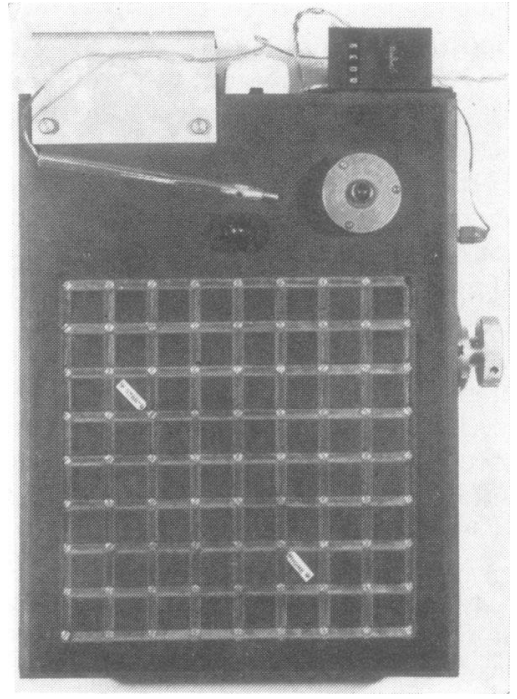

FIG. 2. Visually-guided maze task: apparatus.

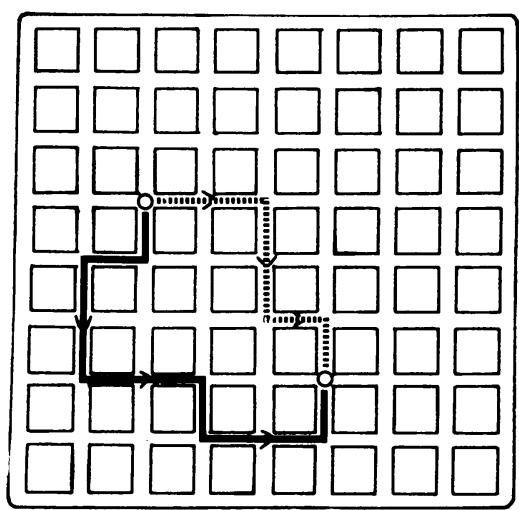

FIG. 3. Visually-guided maze task: schematic representation of paths. 
that the test would be finished when they had completed three successive error-free trials. A maximum of 25 trials was allowed; the maximum score was 23 (that is, criterion reached on the third trial), and one point was deducted for each additional trial required to reach criterion.

\section{RESULTS}

Test data were treated by a fixed-model two-way analysis of variance (Winer, 1962) in which two variables were considered-hemisphere and locus of lesion. The findings for the 'closure' task are shown in Table II : the RH group showed a highly significant deficit. Locus effects did not reach significance but the right temporo-parietal group, which had obtained relatively high scores in intelligence and vocabulary tests, had the lowest mean score of all sub-groups in the experimental sample. The performance of the LH group matched that of the control group (control group I, $N=53$, mean score $=30.00$, $\mathrm{SD}=4 \cdot 33)$.

TABLE II

VISUAL CLOSURE

(a) Mean scores of unilateral groups classified according to locus of lesion

\begin{tabular}{lccccc}
\hline Locus & \multicolumn{1}{c}{$\begin{array}{c}\text { Group } \\
\text { (mean score) }\end{array}$} & $(n)$ & $\begin{array}{c}\text { RH } \\
\text { (mean score) }\end{array}$ & $(n)$ \\
\hline Frontal & 25.67 & 8 & 29.75 & 9 \\
$\begin{array}{l}\text { Temporal or temporo- } \\
\quad \text { parietal }\end{array}$ & 21.36 & 9 & $31 \cdot 33$ & 11 \\
Parietal & 27.83 & 9 & 28.67 & 6 \\
Posterior & 26.80 & 8 & 29.50 & 5 \\
Mixed & 25.17 & 10 & 33.40 & 6 \\
\hline
\end{tabular}

(b) Fixed model analysis of variance of locus of lesion by hemisphere

\begin{tabular}{lrrr}
\hline Source & $d f$ & \multicolumn{1}{c}{$M S$} & \multicolumn{1}{c}{$F$} \\
\hline Locus of lesion (L) & 4 & $17 \cdot 33$ & 0.48 \\
Hemisphere (H) & 1 & $509 \cdot 84$ & $14.05^{*}$ \\
L $\times$ H & 4 & $55 \cdot 93$ & $1 \cdot 54$ \\
Between subjects within groups & 71 & 36.29 & \\
$* P<0.001$. & & & \\
\hline
\end{tabular}

The results for the maze task are shown in Table III: the $\mathrm{RH}$ group again showed a highly significant deficit. Locus effects did not reach significance, but the right parietal and right posterior sub-groups were inferior to all other sub-groups in this task. The LH group, however, did not differ from the control group (control group II, $\mathrm{N}=43$, mean score $=18 \cdot 05, \mathrm{SD}=3 \cdot 50$ ).

The relationship between visual field defect and performance in the 'closure' and maze task is shown in Tables IV and V, respectively. For the LH group there was clearly no association between visual field defect and impaired test performance. For the RH group, the pattern differed according to the task. In the 'closure' task, the mean score of the seven men with hemianopia did not differ from that of the

TABLE III

VISUALLY GUIDED MAZE-PATH TWO

(a) Mean scores of unilateral groups classified according to locus of lesion

\begin{tabular}{lcccc}
\hline Locus & \multicolumn{1}{l}{$\begin{array}{c}\text { Group } \\
\text { (mean score) }\end{array}$} & $(n)$ & $\begin{array}{c}\text { RH } \\
\text { (mean score) }\end{array}$ & $(n)$ \\
\hline Frontal & $14 \cdot 20$ & 7 & $15 \cdot 86$ & 10 \\
$\begin{array}{l}\text { Temporal or temporo- } \\
\quad \text { parietal }\end{array}$ & $13 \cdot 73$ & 9 & $18 \cdot 11$ & 11 \\
Parietal & $9 \cdot 83$ & 10 & $14 \cdot 70$ & 6 \\
$\begin{array}{l}\text { Posterior } \\
\text { Mixed }\end{array}$ & $5 \cdot 80$ & 8 & $18 \cdot 38$ & 5 \\
\hline
\end{tabular}

(b) Fixed model analysis of variance of locus of lesion by hemisphere

\begin{tabular}{lrrr}
\hline Source & $d f$ & \multicolumn{1}{c}{$M S$} & \multicolumn{1}{c}{$F$} \\
\hline Locus of lesion (L) & 4 & $50 \cdot 60$ & $1 \cdot 43$ \\
Hemisphere (H) & 1 & $524 \cdot 73$ & $14 \cdot 79 *$ \\
L $\times$ H & 4 & 67.82 & $1 \cdot 91$ \\
Between subjects within groups & 71 & 35.48 & \\
$* P<0 \cdot 001$. & & & \\
\hline
\end{tabular}

TABLE IV

VISUAL CLOSURE TASK: MEAN SCORES OF SUBJECTS WITH POST-ROLANDIC LESIONS, CLASSIFIED ACCORDING TO LATERALITY OF LESION AND TYPE OF VISUAL FIELD DEFECT

\begin{tabular}{lcccc}
\hline & \multicolumn{5}{c}{ Group performance } \\
Type of visual field defect & $\begin{array}{l}\text { LH group } \\
\text { (mean })\end{array}$ & $(n)$ & group \\
& $($ mean $)$ & $(n)$ \\
\hline Hemianopia & $31 \cdot 00$ & 4 & 25.00 & 7 \\
Upper quadrantanopia & $35 \cdot 50$ & 4 & 16.00 & 3 \\
Lower quadrantanopia & $31 \cdot 50$ & 4 & 24.20 & 5 \\
Sector defects & $32 \cdot 33$ & 3 & & 0 \\
Nil & 28.00 & 11 & 26.75 & 8 \\
\hline
\end{tabular}

TABLE V

VISUALLY-GUIDED MAZE TASK: MEAN SCORES OF SUBJECTS WITH POST-ROLANDIC LESIONS, CLASSIFIED ACCORDING TO LATERALITY OF LESION AND TYPE OF VISUAL FIELD DEFECT

\begin{tabular}{lccrcc}
\hline & \multicolumn{4}{c}{ Group performance } \\
Type of visual field defect & LH group & RH group \\
& $($ mean $)$ & $(n)$ & $($ mean $)$ & $(n)$ \\
\hline Hemianopia & $18 \cdot 25$ & 4 & 5.00 & 7 \\
Upper quadrantanopia & 16.00 & 4 & 16.67 & 3 \\
Lower quadrantanopia & 19.00 & 4 & 9.6 & 5 \\
Sector defects & 18.33 & 3 & & 0 \\
Nil & $17 \cdot 18$ & 11 & 12.50 & 8 \\
\hline
\end{tabular}


eight men with no visual field defect (as measured by perimetry and Bjerrum screen), whereas the small group of men with left upper quadrantic field defects obtained a very low score. Conversely, in the maze task, the seven men in the $\mathrm{RH}$ group with hemianopia were markedly impaired, whereas the performance of men with upper quadrantic field defects did not differ from that of subjects in the RH group without a field defect.

Data from individual subjects in the RH group with low scores in these tasks (defined as scores in the lowest $20 \%$ of the total RH group distribution) were analysed. These men with marked deficits in the 'closure' or maze-learning tasks all had postRolandic lesions, but there was no overlap in scores between the group of seven men with a marked deficit in the 'closure' task (Group I) and the seven men with a marked maze-learning deficit (Groun II). Their performance was then compared with that of the remaining men in the $\mathrm{RH}$ group with postRolandic lesions (Group III, $\mathrm{N}=9$ ). The data are shown in Table VI.

TABLE VI

CLOSURE AND MAZE TASKS: MEAN SCORES OF CONTROL GROUPS AND SUBJECTS WITH RIGHT POST-ROLANDIC LESIONS

\begin{tabular}{llcll}
\hline \multirow{2}{*}{ Task } & \multicolumn{4}{c}{ Group } \\
& Subjects & with & R. post-Rolandic lesions & Control \\
\cline { 2 - 5 } & Group I & Group II & Group III & \\
\hline Closure & 14.86 & 27.86 & 28.78 & 30.00 \\
Maze & 14.71 & 0.29 & 14.60 & 18.05 \\
& & & & \\
\hline
\end{tabular}

Group I, impaired in the 'closure' task, was as efficient as Group III at maze learning. Conversely, Group II, impaired in maze learning, was as efficient as Group III in the 'closure' task. The fact that there was no overlap in scores between Group I and Group II in the two tasks is significant at beyond the 0.002 level.

The possibility of a different locus of lesion for the three right posterior groups was examined from charts of the missile tracks. Subjects in Group I, impaired in the 'closure' task, were found to have lesions involving the posterior temporal-lobe region, whereas subjects in Group II, impaired in maze learning, had high posterior parietal injuries. Case summaries and data from lateral and anteriorposterior radiographs for individual subjects in these two groups are shown in Tables VIIa and VIIb; the lateral presentation has been charted from the radiograph by a method reported elsewhere
(Russell and Espir, 1961), and the anterior-posterior figure is a tracing from the radiograph.

\section{DISCUSSION}

The experimental tasks established an unequivocal 0 difference between the two groups. The RH group, although unimpaired in standard intelligence tests $\frac{O}{\mathrm{~d}}$. and tests of language functions, showed a significant $\underset{2}{2}$ deficit in these visual-perceptual and spatial tasks. In contrast, the LH group was impaired in language $\overrightarrow{\bar{s}}$ tests but matched a normal group in the non-verbal $\overrightarrow{0}$ tasks. This dissociation of symptoms illustrates hemispheric asymmetry of function, and shows that $\frac{\overline{\bar{c}}}{\overline{\mathrm{s}}}$ highly selective residual deficits are found (more $\overparen{\Phi}$ than 20 years after missile injury) in men whose performance in standard intelligence tests does not $\stackrel{\infty}{ }$ differ from that of the normal population in their $\vec{\circ}$ age group.

The impairment of the RH group in the 'closure' task is further evidence of the association between right hemisphere lesions and non-verbal deficit; Milner $(1958,1964)$ has shown deficits in pattern $\omega_{N}$ identification tasks (including the Mooney faces i material) following right temporal lobectoms, $\omega$ and Warrington and James (1967a) have reporte that neurological patients with right parietal lesion are impaired in a visual-perceptual task involvin the recognition of fragmented line drawings (Gollie 을. 1960). The impairment of the present RH group the maze task fits in with the evidence of riget hemisphere deficits in other types of maze taș (Elithorn, 1955; Benton, Elithorn, Fogel, and Kerr, 1963; Corkin, 1965), trail-making tasks (Reitan and Tarshes, 1959), and spatial tasks whether visuallyor tactually-presented (Corkin, 1965; De Renzi, 1967).

In the present study, the possible influence of $\underset{\overrightarrow{7}}{\overrightarrow{7}}$ visual field defects in these non-verbal tasks has to be $\frac{0}{3}$ considered. There was no evidence, however, that field defects due to injury of the optic radiation were significantly associated with poor performance in the two visually-presented experimental tasks. Certainly no association between visual field defects:and poor performance could be detected in the 3 . LH group, whereas in the $\mathrm{RH}$ group the different $\mathrm{O}$ pattern of response in the two tasks suggested that site of lesion rather than visual field defect was $a_{0}$ significant factor. For example, in the 'closure' task, it was only the small group of men with left upper quadrantic defects that obtained low scores whereas the group with left homonymous hemianopias $N$ obtained a similar mean score to that of men $N$ without visual field defects; this finding suggests that a lesion involving the temporal lobe rather than ${ }^{\omega}$ damage to the optic radiation produces impairment 
in this visual-perceptual task. As far as the maze data were concerned, the low scores of the group with left homonymous hemianopias cannot be attributed to the hemianopia per se, as patients with left posterior lesions and right hemianopias were unimpaired in the task. It is possible, however, that the sequential scanning aspect of the maze was difficult for the former group. Braine (1968) has recently drawn attention to work on the importance of the left to right scanning movement and raised the problem of selective attentiveness to one side of the visual display. Right-sided lesions with a left visual field defect may impede scanning more than lesions in the left hemisphere causing comparable visual field defects. On the other hand, the poor performance of the hemianopic patients in the RH group could be attributed to a critical lesion site which coincidentally involves damage to the optic radiation; but these interpretations are not mutually exclusive. In fact, there is little, if any, evidence in the clinical literature that field defects contribute significantly to poor performance in visual-perceptual tasks. Ettlinger (1960) did not establish a significant correlation between visual sensory efficiency and picture response efficiency; and other studies have not shown an association between visual field defects and performance in visual rezognition tasks (Dorff, Mirsky, and Mishkin, 1965; Warrington and James, 1967b). Moreover, - even tactually-presented spatial tasks have shown deficits in patients with right hemisphere lesions and contralateral field defects (De Renzi, 1967), a finding which illustrates the importance of the posterior area of the right hemisphere for spatial function.

The most interesting aspect of the present findings was the sharp dissociation between Group I and Group II, the fact that the scores of the most severely impaired groups in the 'closure' and maze tasks did not overlap. In the right post-Rolandic group as a whole there was a small negative correlation $\left(r_{s}=-0.32\right)$ in performance in these two tasks, whereas there was a small positive correlation $\left(r_{s}=+0 \cdot 23\right)$ in the left post-Rolandic group. The trend towards zero or negative correlations between perceptual and spatial tasks in subjects with right hemisphere lesions has been found in other studies (Warrington and James, 1967a, b) as well, and suggests dissociated deficits. The present data strongly indicate this probability and thus imply functional differentiation within the right hemisphere.

This evidence of dissociated deficits leads to a consideration of critical locus of lesion. Here certain anatomical differences were observed (see Tables VIIa and VIIb for case summaries of men in the two post-Rolandic groups). Group I cases, those subjects severely impaired in the 'closure' task, had lesions in the posterior temporal lobe which tended to encroach on the confluence of temporal, parietal, and occipital lobes. This finding can be related to Hécaen's observation (1962) that lesions in this area of the right hemisphere are associated with prosopagnosic symptoms, since four of the men in our Group I did in fact show residual difficulties in face recognition. Our results are also consistent with data showing a deficit in the same 'closure' task following posterior temporal-lobe lesions (Milner, personal communication). Furthermore, the anatomical features of our cases in Group I can be considered in relation to recent primate work, in which an association has been reported between posterior temporal-lobe ablations and visual discrimination deficits (Iwai and Mishkin, 1967).

Men in Group II (with a maze-learning deficit) had lesions in the right posterior parietal region, not far from the sagittal line and usually involving the occipital lobes as well. This finding is broadly consonant with clinical observations that high posterior lesions in the right hemisphere may be associated with spatial problems in the more environmental or cartographic sense; and presumably this parietal area is critical for the interplay of body image and visual-spatial orientation. Our observations do not imply, however, that damage to this region in the parietal lobe is a necessary condition for maze-learning deficits; and indeed there is evidence of impaired maze performance after right temporal lobectomy with hippocampal removal (Milner, 1965). The two findings could be attributed to different limiting factors: our right parietal and posterior groups may fail the task because of its spatial aspect, whereas patients with a right temporal hippocampal excision are handicapped by the mnestic aspect of the task. There was some support for this interpretation from the present data. One subject had considerable difficulty with the maze task, although he just avoided inclusion in the bottom $20 \%$ of the $\mathrm{RH}$ group. His lesion did not involve the posterior parietal region; initially he had a focal temporal lobe injury, subsequently complicated by an abscess which was drained and finally excised. More than two decades have elapsed since the injury, but he still loses his way in the City of London in which he has worked since the war. He has been in the same office for several years but cannot visualize its layout well enough to direct a visitor within the building, although he can accompany the inquirer. During the present examination, he obtained average scores in visual-perceptual tasks (closure, pattern matching) and was efficient at spatial tasks-for example 
TABLE VIIa

SUBJECTS WITH RIGHT POST-ROLANDIC LESIONS IN GROUP I

Clinical features

Site of wound

Case No. 189. He was wounded in 1944 at the age of 20. A shell fragment struck him just above the right ear and penetrated over and above the temporal horn of the ventricle. When seen a few hours after injury he was able to answer questions and was found to have severe loss of sensation over the left half of the body, and a complete left homonymous hemianopia. The visual defect cleared to leave a lower quadrantic (segmental) defect. The sensory loss cleared to leave slight impairment only to pain and temperature sense on the left. During the early period he had occasional blackouts and, in 1955, two episodes with loss of consciousness When last examined in 1964, he reported that he had had no blackouts for the previous five years but still had occasional episodes of paraesthesia affecting the left side of the body. He runs a small family business.

Case No. 258. He was wounded in 1944 at the age of 40 . There was a penetrating wound by a small shell fragment just above the right ear which entered the middle of the temporal lobe where it destroyed most of the optic radiation to cause an almost complete and permanent left homonymous hemianopia. A fragment of metal remained in the posterior parietal region. The patient remained fully conscious when wounded. He had no sensorimotor loss but developed frequent grand mal attacks and consequently gave up his job as a greengrocer. When last examined in 1964, he reported that he had been having a few fits a year. He was, however, still unemployed.

Case No. 219. He was wounded in 1944 at the age of 24 . Shell fragments penetrated deeply into the lower right anterior parietal lobe. When seen a few hours later he was conscious but confused. The injury caused a permanent severe sensorimotor hemiplegia and loss of the upper part of the optic radiation, causing a permanent lower left quadrantanopia. At operation the extent of brain destruction was described as amounting to the size of a small apple. There were a few episodes of loss of consciousness and one major convulsion in 1952 , but he has had no attacks since 1960 . He worked for many years as a farm manager but has retired since he was last examined in 1965.

Case No. 25. He was wounded in 1944 at the age of 25. A spent bullet struck the right temporomandibular joint and caused a small penetrating wound of the underlying temporal lobe. No disturbance of function was observed other than paralysis of the face and deafness on the side of wounding. When seen in 1965 the facial paralysis had recovered but the right-sided deafness was complete. There were full visual fields and no sensorimotor loss. He works fulltime as a clerk.

Case No. 549. He was wounded in 1945 at the age of 31. A large metal fragment struck him just anterior to his right ear and penetrated the temporal lobe to cause local damage to the lower part of the optic radiation resulting in a permanent upper quadrantanopic field defect. The wound caused a disturbance of consciousness for a few minutes only. There was no sensorimotor loss but he had blackouts with loss of consciousness about once a month. Personality factors were thought to be partially responsible for his inability to work. He died of coronary thrombosis in 1966, a few months after his last examination; a coroner's necropsy report stated that "the right temporal lobe of the brain contained an area of yellow pigmentation in which a small cyst was found'.

Case No. 148. He was wounded in 1944 at the age of 28 . There was a deeply penetrating wound of the lower right occipital lobe with a metal fragment passing forwards to the temporal lobe below the ventricle and causing a permanent homonymous upper quadrantanopia. He was drowsy for a few days after injury. There was, however, no sensorimotor loss and he did not develop post-traumatic epilepsy. No other neurological changes were found during the last examination in 1964. He works full-time as a clerk.

Case No. 266. He was wounded in 1944 at the age of 28. A large metal fragment penetrated deeply at the junction of the right temporal and occipital lobes and destroyed the optic radiation, causing loss of consciousness and amnesia for several days. The injury led to a permanent left homonymous hemianopia but no sensorimotor disturbance. He had one fit in 1946 but no attacks thereafter. No other neurological changes were found during the last examination in 1964. He has worked for over two decades as a broadcaster.
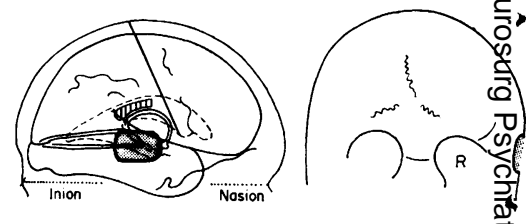

Case No. 189
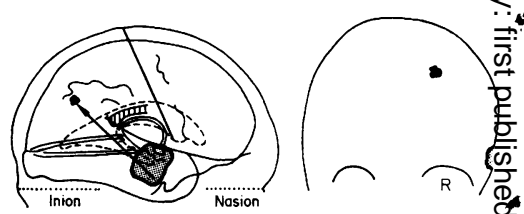

Case No. 258
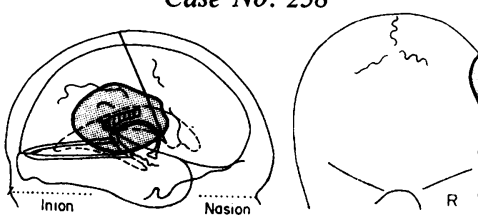

ल)

Case No. 219

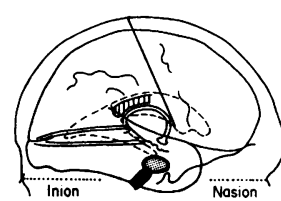

Case No. 25
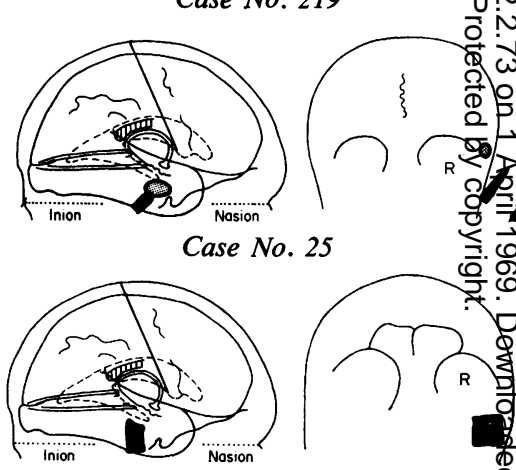

Case No. 549
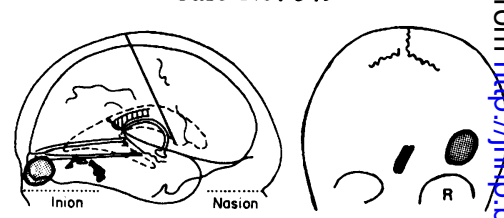

Case No. 148
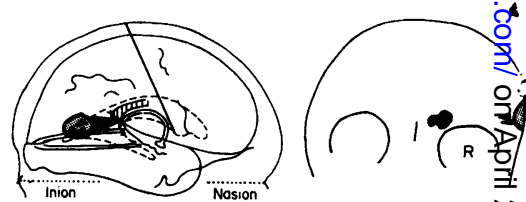

Case No. 266

Missile fragment

$\Delta_{\Delta}$ Bone fragments

(1) Entry wound 
TABLE VIIb

Case No. 571. He was wounded in 1944 at the age of 25 . The missile wound caused no immediate loss of consciousness but penetrated the brain as far as the posterior horn of the right lateral ventricle in the lower posterior parieto-occipital region. Some metal fragments were seen in the radiographs to have reached the upper parieto-occipital region. This wound caused no sensory or motor loss but a left homonymous hemianopia which cleared to a sector-shaped defect. In 1947 he developed a large cerebral abscess which necessitated a complete excision of the right occipital lobe and this caused a complete and permanent hemianopia and a tery slight weakness of the left limbs. Since 1948, he has had grand mal convulsions preceded by sensory features in the left hand, which occur about once a year. In addition, he has brief opisodes three to four times a week, during which he feels unable to use the left side. No other neurological changes were found during the last examination in 1964 . He works full-time as a stockbroker's clerk.

Case No. 328. He was wounded in 1944 at the age of 32. The missile caused little disturbance of consciousness; it penetrated the brain $4 \mathrm{~cm}$ to the right of the sagittal line in the posterior parietal region, $14 \mathrm{~cm}$. from the inion. This caused immediate weakness and numbness of the left leg and some impairment of the left lower visual field, both of which, however, cleared. te had occasional blackouts preceded by tingling in the left arm, but these ceased four to . $v$ ve years before his last examination in 1964 . He works full-time as a metal mechanic.

Case No. 1064. He was wounded in 1941 at the age of 19. An explosion caused a severe head wound and loss of consciousness (amnesia for 10 days). There was a depressed fracture and brain penetration in the right upper parietal region. This caused a sensorimotor left hemiplegia but no impairment of the visual fields. He has had Jacksonian attacks since the njury, at the rate of one to eight a month. The sensorimotor paresis of the left limbs was vermanent. He has lived in a country district, unwilling to travel to attend rehabilitation Jurses. No other neurological changes were found during the last examination in 1964 . He has been classified as unemployable.

Case No. 72. He was wounded in 1944 at the age of 24 . A spent bullet struck the skull and zaused a depressed fracture of the right cccipital bone just below the lambdoid suture and 0 the right of the midline. This caused an area of brain damage measuring $4 \times 2 \times 2 \mathrm{~cm}$ sut consciousness was recovering when seen a few hours after wounding. The only afteriffect was a permanent and almost complete left homonymous hemianopia. He had one fit juring convalescence but none since. No other neurological changes were found during

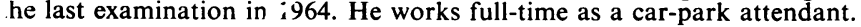

Zase No. 1085. He was wounded in 1942 at the age of 24. A missile penetrated the skull ust to the right of the lambdoid suture, injured the underlying occipital and posterior parietal obe and caused unconsciousness with amnesia for several days. This wound later formed in intra-cerebral abscess which was successfully controlled, but resulted in a permanent left Iomonymous hemianopia. Post-traumatic epilepsy developed. When last examined in 1965, te reported occasional fits, preceded by a visual aura, and followed by brief loss of conciousness. He works full-time as a clerk.

Case No. 551. He was wounded in 1943 at the age of 31. A missile penetrated the right ccipito-posterior parietal region and caused partial unconsciousness and an area of brain estruction immediately below the wound and extending to the posterior horn of the lateral entricle. There was, however, no paresis or sensory loss in the limbs at any time, but a ermanent lower quadrantic field defect resulted. No other neurological changes were found uring the last examination in 1965 . He works full-time at a store-keeping and maintenance sb.

ase No. 87. He was wounded in 1944 at the age of 19. He sustained a deep, through-andirough occipito-parietal wound above the level of the transverse sinus. There was little isturbance of consciousness. The injury caused a division of the optic radiation with a ermanent complete homonymous hemianopia, but no permanent sensorimotor loss. Two ionths later a right ventricular cyst was successfully treated. No sensorimotor changes :sulted and he was discharged five months after the injury. No other neurological changes ere found during the last examination in 1965. He works full-time as a clerk.

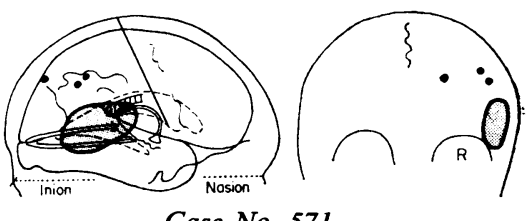

Case No. 571
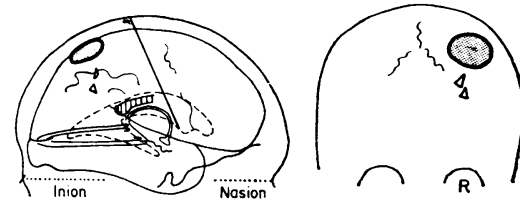

Case No. 328
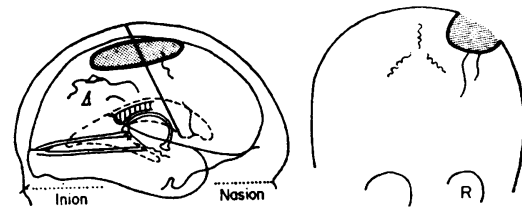

Case No. 1064
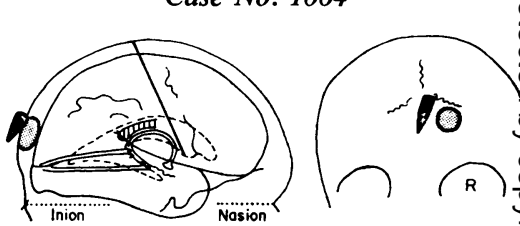

Case No. 72

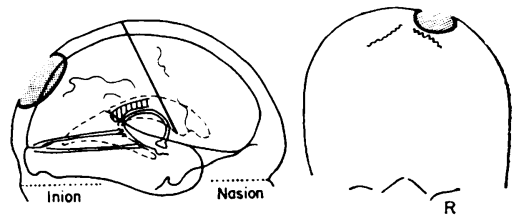

Case No. 1085
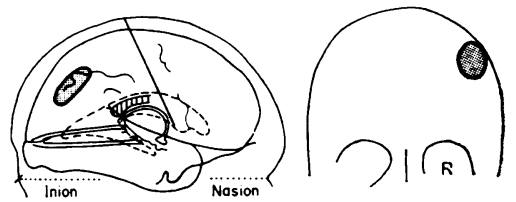

Case No. 551
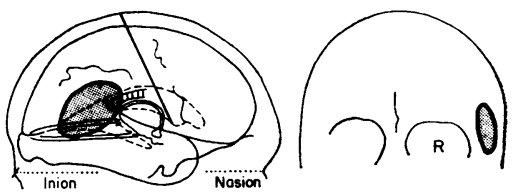

Case No. 87

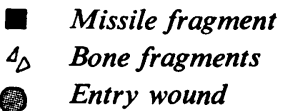


block design, cube analysis. Thus, it seems likely that his difficulty with the maze task was attributable to an impairment of visual memory of the type he himself described.

Were there any clues from the data as to the nature of the functions impaired by these right posterior lesions? In the present study, the 'closure' deficit could not be related to spatial difficulties in view of the adequate scores of Group $I$ in the maze task and in a related visual-spatial task (cube analysisTerman and Merrill, 1937). But the hypothesis of a visual-perceptual deficit, connected with the process of integrating simultaneous visual input, seems feasible. In this context one subject in the group described his visual impressions during the acute phase as 'rather like sitting in a crowded railway carriage looking out of the window and catching unconnected glimpses of people and things which had always disappeared before one had realized quite what was happening'.

There may also be a link between the closure deficit and residual prosopagnosic symptoms. In the total experimental sample, only six men reported such symptoms and four of them were in Group I; two members of this group had been handicapped professionally by their inability to recognize the faces of clients and colleagues, while the third was the only member of his family unable to identify his 4-year-old twins apart. While these residual difficulties in face recognition could be attributed to perceptual or mnestic factors or indeed a combination of them, there was no evidence from performance in other tasks that the four subjects concerned were specifically handicapped in visual retention.

Concerning the maze-learning deficit, subjects in Group II were not selectively impaired in perceptual tasks-for example, closure and visual pattern matching-nor did they present with symptoms of pericalcarine lesions such as inattention and disorientation in visual hemi-fields. The most severe instances of localization and inattention difficulties in this experimental population have not been specifically impaired in maze-learning compared with the remaining subjects with right posterior lesions. A possible explanation of the maze deficit is that of a more generalized mnestic disturbance, and accordingly the performance of the three right posterior groups in a verbal learning task (Inglis, 1957) was examined. The evidence was not clear-cut; the mean score of Group II was lower than that of the remaining groups and the control group, but the differences did not reach statistical significance. Examination of individual cases within Group II showed a bimodal distribution. Three men failed the verbal learning task but the remaining four achieved relatively high scores. Two of the three men who failed the verbal learning task had comparatively large lesions, while the third subject was of well below average intelligence. Thus, while there was no definite evidence that the maze-learning deficit was associated with a generalized learning deficit it is possible that the factor of lesion size may be a relevant variable in learning and retention tasks, as has been suggested by previous workers (McFie and Piercy, 1952; Milner, 1965). There was more evidence for the view that the maze-learning deficit was related to spatial difficulties. Group II obtained a significantly low score in an untimed version of the Progressive Matrices test (Raven, 1960), and low scores in cube counting (Terman and Merrill, 1937), and block design (Wechsler, 1955).

In conclusion, the present study produced evidence of dissociated deficits in men with right postRolandic lesions. The further exploration of these deficits requires a more precise definition of the parameters involved in visual-perceptual and spatial tasks, and of the different limiting factors that underlie impairment. This may include a comparison between performance in visual-perceptual tasks on the one hand and visual memory tasks on the other, along the lines recently investigated in experimental primate work (Gross and Cowey, 1967; Iwai and Mishkin, 1967), as well as a more refined analysis of problems of spatial orientation.

\section{SUMMARY}

Men with brain lesions due to missile injury in the second world war have been re-examined, neurologically and psychologically, more than 20 years later, as part of an on-going study of the long-term sequelae of these injuries. The present paper reports the performance of 44 men with unilateral lesions of the left hemisphere and 37 men with right hemisphere lesions in two visually-presented tasks, face identification ('closure') and maze-learning. The group with right hemisphere lesions was significantly impaired in both tasks, whereas the group with lesions in the left hemisphere performed as well as normal control subjects. There was also evidence of dissociated deficits within the group of men with right post-Rolandic lesions: there was no overlap in scores of the men most severely impaired in 'closure' and those most severely impaired in maze-learning. The anatomical characteristics and some other features of these different groups are discussed; and the data are considered to support the concepts of hemispheric asymmetry and of functional differentiation within the hemisphere.

We wish to thank Dr. Brenda Milner for several helpful discussions, Dr. H. Lansdell for kindly supplying the 
'closure' test material, and Dr. E. H. J. Schuster who designed and constructed the maze.

\section{REFERENCES}

Anderson, A. L. (1951). The effect of laterality localization of focal brain lesions on the Wechsler-Bellevue subtests. $J$. clin. Psychol., 7, 149-153.

Benton, A. L., Elithorn, A., Fogel, M. L., and Kerr, M. (1963). A perceptual maze test sensitive to brain damage. J. Neurol. Neurosurg. Psychiat., 26, 540-544.

Braine, L. G. (1968) Asymmetries of pattern perception observed in Israelis. Neuropsychologia, 6, 73-88.

Corkin, S. (1965). Tactually-guided maze learning in man: effects of unilateral cortical excisions and bilateral hippocampal lesions. Neuropsychologia, 3, 339-351.

Costa, L. D., and Vaughan, H. G., Jnr. (1962). Performance of patients with lateralized cerebral lesions. I. Verbal and perceptual tests. J. nerv. ment. Dis., 134, 162-168.

Critchley, M. (1953). The Parietal Lobes. Arnold: London.

Dé Renzi, E. (1967). Asimmetrie emisferiche nella rappresentazione non verbali. Extract from: Atti del XVI Congresso Nazionale di Neurologia (Roma, 23-26 Oct. 1967), 1, 371-430.

Dide, M. (1938). Les désorientations temporo-spatiales et la prépondérance de l'hémisphère droit dans les agnosoakinésies proprioceptives. Encéphale, 2, 276-294.

Dorff, J. E., Mirsky, A. F., and Mishkin, M. (1965). Effects of unilateral temporal lobe removals in man on tachistoscopic recognition in the left and right visual fields. Neuropsychologia, $3,39-51$.

Elithorn, A. (1955). A preliminary report on a perceptual maze test sensitive to brain damage. J. Neurol. Neurosurg. Psychiat., 18, 287-292.

Ettlinger, G. (1960). The description and interpretation of pictures in cases of brain lesion. J. ment. Sci., 106, 1337-1346.

-, Warrington. E., and Zangwill, O. L. (1957). A further study of visual-spatial agnosia. Brain, 80, 335-361.

Gollin, E. S. (1960). Developmental studies of visual recognition of incomplete objects. Percept. Mot. Skills, 11, 289-298.

Gross, C. G., and Cowey, A. (1967). Electrophysiological and Ablation Experiments on Inferotemporal Cortex: a Progress Report. Paper read in September, 1967 at Amer. Psychol. Ass., Washington, D.C.

Hécaen, H. (1962). Clinical symptomatology in right and left hemispheric lesions. Pp. 215-243 in Interhemispheric Relations and Cerebral Dominance. Edited by V. B. Mountcastle. Johns Hopkins: Baltimore.

- Ajuriaguerra, J. de, and Massonnet, J. (1951). Les troubles visuo-constructifs par lésion pariéto-occipitale droite: rôle des perturbations vestibulaires. Encéphale, 40, 122-179.

Inglis, J. (1957). An experimental study of learning and 'memory function' in elderly psychiatric patients. J. ment. Sci., 103, 796-803.

Iwai, E., and Mishkin, M. (1967). Two Inferotemporal Foci for Visual Functions. Paper read in September, 1967 at Amer. Psychol. Ass., Washington, D.C.

Jackson, J. H. (1887). Cited by Head, H. (1915). Brain, 38, p. 6.

Kimura, D. (1963). Right temporal-lobe damage. Perception of unfamiliar stimuli after damage. Arch. Neurol. (Chic.), 8, 264-271.

Lange, J. (1936). Agnosien und Apraxien. Pp. 807-960 in Handbuch der Neurologie, Vol. VI. Edited by O. Bumke and O. Foerster. Springer: Berlin.

Lansdell, H. C. (1961). Two Selective Deficits Found to be Lateralized in Temporal Neurosurgery Putients. Paper read at 32nd Ann. Meeting, Eastern Psychol. Ass., Philadelphia.
Landsell, H. (1968). Effect of extent of temporal lobe ablations on two lateralized deficits. Physiol. Behav., 3, 271-273.

McFie, J., and Piercy, M. F. (1952). Intellectual impairment with localized cerebral lesions. Brain, 75, 292-311.

,-- and Zangwill, O. L. (1950). Visual-spatial agnosia associated with lesions of the right cerebral hemisphere. Brain, $73,167-190$.

Meier, M. J., and French, L. A. (1965). Lateralized deficits in complex visual discrimination and bilateral transfer of reminiscence following unilateral temporal lobectomy. Neuropsychologia, 3, 261-272.

Milner, B. (1952). Intellectual Effects of Temporal-Lobe Damage in Man. Doctoral Thesis, McGill University.

- (1958). Psychological defects produced by temporal lobe excision. Res. Publs Ass. nerv. ment. Dis., 36, 244-257.

(1963). Effects of different brain lesions on card sorting: the rôle of the frontal lobes. Arch. Neurol. (Chic.), 9, 90-100.

- (1964). Discussion on paper by M. Mishkin, 'Prestriate cortex and the organization of the visual system'. Acta Psychol. (Amst.), 23, 306-308.

(1965). Visually-guided maze learning in man: effects of bilateral hippocampal, bilateral frontal, and unilateral cerebral lesions. Neuropsychologia, 3, 317-338.

(1967). Brain mechanisms suggested by studies of temporal lobes. Pp. 122-145 in Brain Mechanisms Underlying Speech and Language. Edited by F. L. Darley. Grune and Stratton: New York.

Mooney, C. M. (1956). Closure with negative after-images under flickering light. Canadian J. Psychol., 10, 191-199.

- (1957). Closure as affected by configural clarity and contextual consistency. Canadian J. Psychol., 11, 80-88.

Newcombe, F. (1969). Missile Wounds of the Brain: a Study of Psychological Deficits. Oxford University Press: Oxford. In press.

Paterson, A., and Zangwill, O. L. (1944). Disorders of visual space perception associated with lesions of the right cerebral hemisphere. Brain, 67, 331-358.

Piercy, M. (1964). The effects of cerebral lesions on intellectual function: a review of current research rends. Brit. J. Psychiat., 110, 310-352.

Pötzl, O. (1928). Die Aphasielehre vom Standpunkte der klinischen Psychiatrie. Bd. 1. Die verschiedenen Formen der Seelenblindheit. Deuticke: Leipzig.

Raven, J. C. (1960). Guide to the Standard Progressive Matrices. Lewis, London.

Reitan, R. M., and Tarshes, E. L. (1959). Differential effects of lateralized brain lesions on the trail making test. J. nerv. ment. Dis., 129, 257-262.

Russell, W. R. (1947). The neurology of brain wounds. Brit. J. Surg., War Surgery Suppl. No. 1, 250-252.

_ and Espir, M. L. E. (1961). Traumatic Aphasia.A Study of Aphasia in War Wounds of the Brain. Oxford University Press: London.

Terman, L. M., and Merrill, M. A. (1937). Measuring Intelligence. Harrap: London.

Teuber, H.-L. (1962). Effects of brain wounds implicating right or left hemisphere in man: hemisphere differences and hemisphere interaction in vision, audition, and somesthesis. Pp. 131-157 in Interhemispheric Relations and Cerebral Dominance. Edited by V. B. Mountcastle. Johns Hopkins: Baltimore.

Warrington, E. K., and James, M. (1967a). Disorders of visual perception in patients with localized cerebral lesions. Neuropsychologia, 5, 253-266.

,$- \quad(1967 \mathrm{~b})$. An experimental investigation of facial recognition in patients with unilateral cerebral lesions. Cortex, 3, 317-326.

Wechsler, D. (1955). Wechsler Adult Intelligence Scale Manual. Psychological Corporation: New York.

Winer, B. J. (1962). Statistical Principles in Experimental Design. McGraw-Hill: New York. 
STUDIES OF ANXIETY Papers read at the World Psychiatric Association Symposium, 'Aspects of Anxiety', London, November 1967. (British Journal of Psychiatry Special Publication, No. 3.) Edited by M. H. Lader. (Pp. vi + 166; illustrated. 30s.) Headley: Ashford, Kent, 1969.

The quality of papers read at even a small symposium tends to vary widely, some seeming to be spoken off the cuff, and others reporting work in progress that does not merit completion. In this collection there are many contributors who have plainly done their homework, notably Eysenck (psychological aspects), Smythies (neurophysiology), Levi (neuroendocrinology), Slater and Shields (genetics), Hamilton (diagnosis), Murray Parkes (separation anxiety), Gelder (behaviour therapy), Greer (prognosis), and the editor himself (psychophysiology). In these papers scientific study takes precedence over earlier habits of speculation, and gives hope for real progress in the study of anxiety.

$$
\text { R. T. C. PRATT }
$$

\section{BOOKS RECEIVED}

(Books noticed here may also be reviewed in a later issue)

NON-SPECIFIC FACTORS IN DRUG THERAPY Compiled and edited by Karl Rickels. (Pp. xii +149 ; illustrated. \$7.75). Thomas: Springfield, Illinois. 1968.

What is PSychoanalysis? Edited by Walter G. Joffe. (Pp. iii +65 . 10s.) Ballière, Tindall and Cassell: London. 1969.

W.H.O. EXPERT COMMITTEE ON DRUG DEPENDENCE-16th Report. W.H.O. Technical Report Series, No. 407. (Pp. 28. 4s.) W.H.O.: Geneva. 1969.

AKTUELLE OTO-RHINO-LARYNGOLOGIE. Heft 1: Die Hypoxydose der Kochlea durch Kohlenmonoxtyd By G. Kittel; \& Zytodiagnostische Untersuchungen im Bereich der oberen Luftwege By E. Ruppmann. (Pp. v +88 ; illustrated. DM 39.) Thieme: Stuttgart. 1969.

\section{NOTICES}

\section{'CEREBELLUM'}

The 4th Symposium of the Fulton Society on 'Cerebellum' will take place on 20 September 1969, New York City. Details may be obtained from Dr. Victor Soriano, Calle Buenos Aires 363, Montevideo, Uruguay.

\section{THIRD EUROPEAN SYMPOSIUM ON EPILEPSY}

This symposium, arranged by the International Bureau for Epilepsy, the International League against Epilepsy, and the Danish Epilepsy Association, will take place at Hotel Marienlyst, Elsinore (near Copenhagen), Denmark, on 21 to 23 June 1970. Details from DIS Congress Service, 36 Skindergade, DK-1159 Copenhagen K, Denmark.

\section{WORLD MENTAL HEALTH ASSEMBLY}

The World Mental Health Assembly, jointly sponsored by the World Federation for Mental Health, will take place in Washington, D.C., 17 to 21 November 1969. Details may be obtained from Dr. Paul V. Lemkau, Chairman, W.M.H.A., 615 N. Wolfe Street, Baltimore, Maryland, 21205.

\section{IVTH INTERNATIONAL CONGRESS OF PSYCHOSOMATIC MEDICINE}

This International Congress of Psychosomatic Medicine, organized by the French Society of Psychosomatic Medicine, will be held in Paris from 17 to 20 September 1970, on 'The Psychotherapeutic Action of the Physician'. Summaries of papers must be submitted by 30 October 1969. Details may be obtained from S.O.C.F.I., 7 rue Michel-Ange, Paris 16․, France.

\section{CORRECTION}

In the paper 'Dissociated visual perceptual and spatial deficits in focal lesions of the right hemisphere', by Freda Newcombe and W. Ritchie Russell (J. Neurol. Neurosurg. Psychiat., 32, 73-81) the columns of mean scores for the $\mathbf{L H}$ and $\mathbf{R H}$ experimental groups were transposed in Tables II(a) and III(a) (p. 75). The Tables should read as follows:

TABLE II

VISUAL CLOSURE

(a) Mean scores of unilateral groups classified according to locus of lesion

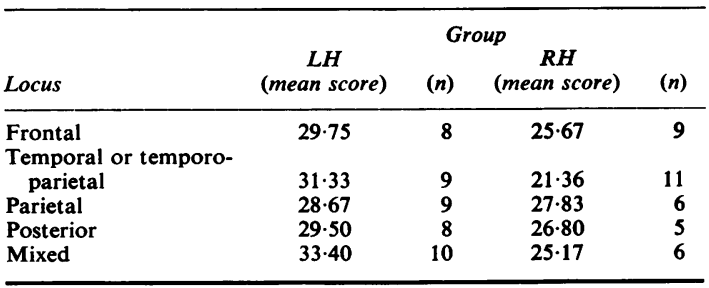

TABLE III

VISUALLY GUIDED MAZE-PATH TWO

(a) Mean scores of unilateral groups classified according to locus of legion

\begin{tabular}{|c|c|c|c|c|}
\hline \multirow[b]{2}{*}{ Locus } & \multicolumn{4}{|c|}{ Group } \\
\hline & $\begin{array}{c}L H \\
\text { (mean score) }\end{array}$ & (n) & $\begin{array}{c}R H \\
\text { (mean score) }\end{array}$ & $(n)$ \\
\hline $\begin{array}{l}\text { Frontal } \\
\text { Temporal or temporo- }\end{array}$ & $15 \cdot 86$ & 7 & $14 \cdot 20$ & 10 \\
\hline parietal & $18 \cdot 11$ & 9 & $13 \cdot 73$ & 11 \\
\hline Parietal & $14 \cdot 70$ & 10 & 9.83 & 6 \\
\hline Posterior & $18 \cdot 38$ & 8 & $5 \cdot 80$ & 5 \\
\hline Mixed & $17 \cdot 00$ & 10 & $14 \cdot 00$ & 5 \\
\hline
\end{tabular}

